\title{
Commentary: The m-AAA Protease Associated with Neurodegeneration Limits MCU Activity in Mitochondria
}

\author{
Paolo Bernardi ${ }^{1 *}$ and Michael Forte ${ }^{2 *}$ \\ ${ }^{1}$ Department of Biomedical Sciences, University of Padova, Padova, Italy, ${ }^{2}$ Vollum Institute, Oregon Health and Science \\ University, Portland, OR, USA
}

Keywords: mitochondria, proteases, calcium uniporter, permeability transition pore, neurodegenerative diseases

\section{A commentary on}

The m-AAA Protease Associated with Neurodegeneration Limits MCU Activity in Mitochondria

by König, T., Tröder, S. E., Bakka, K., Korwitz, A., Richter-Dennerlein, R., Lampe, P. A., et al. (2016). Mol. Cell 64, 1-15. doi: 10.1016/j.molcel.2016.08.020

\section{OPEN ACCESS}

Edited by:

Gyorgy Hajnoczky,

Thomas Jefferson University, USA

Reviewed by:

Shey-Shing Sheu,

University of Rochester, USA

Jan B. Hoek,

Thomas Jefferson University, USA

${ }^{*}$ Correspondence:

Paolo Bernardi

bernardi@bio.unipd.it

Michael Forte

forte@ohsu.edu

Specialty section:

This article was submitted to

Mitochondrial Research,

a section of the journal

Frontiers in Physiology

Received: 29 September 2016 Accepted: 14 November 2016 Published: 25 November 2016

Citation:

Bernardi $P$ and Forte M (2016) Commentary: The m-AAA Protease Associated with Neurodegeneration Limits MCU Activity in Mitochondria.

Front. Physiol. 7:583

doi: 10.3389/fphys.2016.00583
SPG7 and AFG3L are $m$-AAA proteases that form homo-oligomeric complexes and perform essential functions in mitochondrial quality control (Quirós et al., 2015). Mutations of the SPG7 and AFG3L genes cause an autosomal recessive form of hereditary spastic paraplegia (Casari et al., 1998) and spinocerebellar ataxia (Atorino et al., 2003; Di Bella et al., 2010), respectively, as well as other neurological syndromes (Pierson et al., 2011). Mitochondrial dysfunction plays a fundamental role in disease onset, as suggested by decreased activity of respiratory complex I and increased sensitivity to reactive oxygen species (Atorino et al., 2003). König et al. now show that $m$-AAA proteases assist in the correct formation of the mitochondrial $\mathrm{Ca}^{2+}$ uniporter (MCU) complex by regulating the levels of its essential subunit EMRE (König et al., 2016). The study provides a potential mechanistic link between $m$-AAA protease dysfunction, deregulation of $\mathrm{Ca}^{2+}$ homeostasis and opening of the permeability transition pore (PTP), a high conductance channel that requires matrix $\mathrm{Ca}^{2+}$ and is stimulated by oxidative stress (Bernardi et al., 2015). The suggestion that SPG7 is part of the PTP (Shanmughapriya et al., 2015) is seriously questioned by the findings of the article covered in this editorial, supporting the view outlined in a previous commentary (Bernardi and Forte, 2015).

In energized mitochondria the $\mathrm{Ca}^{2+}$ electrochemical gradient drives $\mathrm{Ca}^{2+}$ uptake through the MCU (Baughman et al., 2011; De Stefani et al., 2011). MCU function is affected by the regulatory subunits MICU1 (Perocchi et al., 2010), MICU2 (Plovanich et al., 2013), the MCU inhibitory paralog MCUb (Raffaello et al., 2013) and EMRE (Sancak et al., 2013), a sensor for matrix $\mathrm{Ca}^{2+}$ and a critical gatekeeper for the MCU (Vais et al., 2016). In the absence of EMRE (which faces the matrix) MCU currents are no longer inhibited by matrix $\mathrm{Ca}^{2+}$ (which would normally limit its accumulation) resulting in enhanced mitochondrial $\mathrm{Ca}^{2+}$ uptake and elevation of matrix $\left[\mathrm{Ca}^{2+}\right]$ (Vais et al., 2016). It was already known (and somewhat puzzling) that EMRE-dependent regulation of MCU channel activity requires both MICU1 and MICU2, which are localized on the opposite side of the inner membrane and face the intermembrane space (Vais et al., 2016). The results of König et al. bear on this issue with the novel finding that EMRE is a substrate of $m$-AAA proteases in the intermembrane space before its import and incorporation into the MICU1-MICU2 complex during the dynamic processes that ultimately generate the complete, regulated MCU complex. In the absence of adequate $m$-AAA protease activity, the excess EMRE associates with the MCU in a complex that lacks MICU1 and MICU2 (König et al., 2016). This unprocessed, unregulated 
MCU-EMRE complex would not be inhibited by matrix $\mathrm{Ca}^{2+}$ and thus mediate excessive mitochondrial $\mathrm{Ca}^{2+}$ uptake, leading to opening of the PTP and to all its detrimental consequences linked to deregulation of $\mathrm{Ca}^{2+}$ homeostasis and ATP depletion (Bernardi et al., 2015). Consistent with this picture, mitochondria from HeLa cells and from mice lacking SPG7 and/or AFG3L displayed increased sensitivity to $\mathrm{Ca}^{2+}$-induced PTP opening (König et al., 2016), as measured with the $\mathrm{Ca}^{2+}$ retention capacity (CRC) assay, i.e., the amount of $\mathrm{Ca}^{2+}$ needed to trigger pore opening. This is the opposite of what was reported by Shanmughapriya et al. who carried out a phenotypic screen of the CRC in permeabilized cells after inactivation of a variety of genes. According to this report, SPG7 downregulation desensitized the PTP by rendering it less sensitive to $\mathrm{Ca}^{2+}$ (Shanmughapriya et al., 2015). In contrast, König et al. find that depletion of SPG7 facilitated PTP opening under all conditions tested (König et al., 2016). Irrespective of the basis for this discrepancy, which might depend on complementation by homo-oligomeric AFG3L2 and will need further investigation, the predictions of the two sets of opposing findings can be matched against the known hallmarks of diseases linked to mutations of $m$-AAA proteases.

Mitochondrial dysfunction is of pathogenic relevance to neurodegenerative disorders due to mutations of $m$-AAA proteases. This is clearly indicated by the presence of abnormal, often swollen mitochondria (Casari et al., 1998; Atorino et al., 2003; Ferreirinha et al., 2004; Di Bella et al., 2010; Almajan et al., 2012), which is the expected outcome of PTP opening (Bernardi et al., 2015). The second element is derangement of $\mathrm{Ca}^{2+}$ homeostasis since both downregulation of the glutamate receptor, which mediates $\mathrm{Ca}^{2+}$-dependent PTP

\section{REFERENCES}

Almajan, E. R., Richter, R., Paeger, L., Martinelli, P., Barth, E., Decker, T., et al. (2012). AFG3L2 supports mitochondrial protein synthesis and Purkinje cell survival. J. Clin. Invest. 122, 4048-4058. doi: 10.1172/JCI64604

Atorino, L., Silvestri, L., Koppen, M., Cassina, L., Ballabio, A., Marconi, R., et al. (2003). Loss of m-AAA protease in mitochondria causes complex I deficiency and increased sensitivity to oxidative stress in hereditary spastic paraplegia. $J$. Cell Biol. 163, 777-787. doi: 10.1083/jcb.200304112

Banfi, S., Bassi, M. T., Andolfi, G., Marchitiello, A., Zanotta, S., Ballabio, A., et al. (1999). Identification and characterization of AFG3L2, a novel parapleginrelated gene. Genomics 59, 51-58. doi: 10.1006/geno.1999.5818

Baughman, J. M., Perocchi, F., Girgis, H. S., Plovanich, M., Belcher-Timme, C. A., Sancak, Y., et al. (2011). Integrative genomics identifies MCU as an essential component of the mitochondrial calcium uniporter. Nature 476, 341-345. doi: $10.1038 /$ nature 10234

Bernardi, P., and Forte, M. (2015). Commentary: SPG7 is an essential and conserved component of the mitochondrial permeability transition pore. Front. Physiol. 6:320. doi: 10.3389/fphys.2015.00320

Bernardi, P., Rasola, A., Forte, M., and Lippe, G. (2015). The mitochondrial permeability transition pore: channel formation by F-ATP Synthase, integration in signal transduction, and role in pathophysiology. Physiol. Rev. 95, 1111-1155. doi: 10.1152/physrev.00001.2015

Casari, G., De Fusco, M., Ciarmatori, S., Zeviani, M., Mora, M., Fernandez, P., et al. (1998). Spastic paraplegia and OXPHOS impairment caused by mutations in paraplegin, a nuclear-encoded mitochondrial metalloprotease. Cell 93, 973-983. doi: 10.1016/\$0092-8674(00)81203-9

De Stefani, D., Raffaello, A., Teardo, E., Szabó, I., and Rizzuto, R. (2011). A forty-kilodalton protein of the inner membrane is the opening (Schinder et al., 1996), and decrease of cytosolic $\left[\mathrm{Ca}^{2+}\right]$ suppressed ataxia in an AFG3L2-deficent mouse (Maltecca et al., 2015). Thus, the pathological alterations are best explained by PTP sensitization (König et al., 2016) rather than by PTP inhibition (Shanmughapriya et al., 2015). It should be noted that decreased activity of respiratory complex I and increased reactive oxygen species (Atorino et al., 2003) can cause sensitization to PTP opening even if the increase of mitochondrial $\left[\mathrm{Ca}^{2+}\right]$ is not large (e.g., Figure 6C). m-AAA proteases possess only 2 hydrophobic regions (Casari et al., 1998; Banfi et al., 1999) and are therefore unlikely to form high-conductance channels. We think that this missing piece of evidence, which is essential to substantiate the claim that SPG7 is a constituent of the PTP (Shanmughapriya et al., 2015), should be provided before this hypothesis can be considered further. For the time being we believe that an indirect, PTP inducing effect of defective $m$-AAA proteases is the most plausible explanation for the pathogenesis of neurological diseases due to mutations in their genes. Formation of deregulated MCU complexes provides a provocative but testable mechanism for the increased probability of PTP opening.

\section{AUTHOR CONTRIBUTIONS}

$\mathrm{PB}$ and MF wrote the commentary.

\section{ACKNOWLEDGMENTS}

Research in our laboratories is supported by Telethon, AIRC, $\mathrm{NIH}$ and the Leducq Foundation.

mitochondrial calcium uniporter. Nature 476, 336-340. doi: 10.1038/nature 10230

Di Bella, D., Lazzaro, F., Brusco, A., Plumari, M., Battaglia, G., Pastore, A., et al. (2010). Mutations in the mitochondrial protease gene AFG3L2 cause dominant hereditary ataxia SCA28. Nat. Genet. 42, 313-321. doi: 10.1038/ ng. 544

Ferreirinha, F., Quattrini, A., Pirozzi, M., Valsecchi, V., Dina, G., Broccoli, V., et al. (2004). Axonal degeneration in paraplegin-deficient mice is associated with abnormal mitochondria and impairment of axonal transport. J. Clin. Invest. 113, 231-242. doi: 10.1172/JCI200420138

König, T., Tröder, S. E., Bakka, K., Korwitz, A., Richter-Dennerlein, R., Lampe, P. A., et al. (2016). The m-AAA Protease Associated with Neurodegeneration Limits MCU Activity in Mitochondria. Mol. Cell 64, 1-15. doi: 10.1016/j.molcel.2016.08.020

Maltecca, F., Baseggio, E., Consolato, F., Mazza, D., Podini, P., Young, S. M. Jr., et al. (2015). Purkinje neuron $\mathrm{Ca}^{2+}$ influx reduction rescues ataxia in SCA28 model. J. Clin. Invest. 125, 263-274. doi: 10.1172/JCI74770

Perocchi, F., Gohil, V. M., Girgis, H. S., Bao, X. R., McCombs, J. E., Palmer, A. E., et al. (2010). MICU1 encodes a mitochondrial EF hand protein required for $\mathrm{Ca}^{2+}$ uptake. Nature 467, 291-296. doi: 10.1038/nature09358

Pierson, T. M., Adams, D., Bonn, F., Martinelli, P., Cherukuri, P. F., Teer, J. K., et al. (2011). Whole-exome sequencing identifies homozygous AFG3L2 mutations in a spastic ataxia-neuropathy syndrome linked to mitochondrial m-AAA proteases. PLoS Genet. 7:e1002325. doi: 10.1371/journal.pgen.10 02325

Plovanich, M., Bogorad, R. L., Sancak, Y., Kamer, K. J., Strittmatter, L., Li, A. A., et al. (2013). MICU2, a paralog of MICU1, resides within the mitochondrial uniporter complex to regulate calcium handling. PLoS ONE 8:e55785. doi: 10.1371/journal.pone.0055785 
Quirós, P. M., Langer, T., and López-Otín, C. (2015). New roles for mitochondrial proteases in health, ageing and disease. Nat. Rev. Mol. Cell Biol. 16, 345-359. doi: $10.1038 / \mathrm{nrm} 3984$

Raffaello, A., De Stefani, D., Sabbadin, D., Teardo, E., Merli, G., Picard, A., et al. (2013). The mitochondrial calcium uniporter is a multimer that can include a dominant-negative pore-forming subunit. EMBO J. 32, 2362-2376. doi: 10.1038/emboj.2013.157

Sancak, Y., Markhard, A. L., Kitami, T., Kovacs-Bogdan, E., Kamer, K. J., Udeshi, N. D., et al. (2013). EMRE is an essential component of the mitochondrial calcium uniporter complex. Science 342, 1379-1382. doi: 10.1126/science.1242993

Schinder, A. F., Olson, E. C., Spitzer, N. C., and Montal, M. (1996). Mitochondrial dysfunction is a primary event in glutamate neurotoxicity. J. Neurosci. 16, 6125-6133.

Shanmughapriya, S., Rajan, S., Hoffman, N. E., Higgins, A. M., Tomar, D., Nemani, N., et al. (2015). SPG7 Is an essential and conserved component of the mitochondrial permeability transition pore. Mol. Cell 60, 47-62. doi: 10.1016/j.molcel.2015. 08.009
Vais, H., Mallilankaraman, K., Mak, D. O., Hoff, H., Payne, R., Tanis, J. E., et al. (2016). EMRE Is a Matrix $\mathrm{Ca}^{2+}$ sensor that governs gatekeeping of the mitochondrial $\mathrm{Ca}^{2+}$ uniporter. Cell Rep. 14, 403-410. doi: 10.1016/j.celrep.2015.12.054

Conflict of Interest Statement: The authors declare that the research was conducted in the absence of any commercial or financial relationships that could be construed as a potential conflict of interest.

The reviewer $\mathrm{JH}$ and handling Editor declared their shared affiliation, and the handling Editor states that the process nevertheless met the standards of a fair and objective review.

Copyright (c) 2016 Bernardi and Forte. This is an open-access article distributed under the terms of the Creative Commons Attribution License (CC BY). The use, distribution or reproduction in other forums is permitted, provided the original author(s) or licensor are credited and that the original publication in this journal is cited, in accordance with accepted academic practice. No use, distribution or reproduction is permitted which does not comply with these terms. 